\title{
Uma proposta de universidade corporativa pautada nos pilares educação corporativa, gestão do conhecimento e gestão da inovação
}

\section{A proposal for corporate university based on the pillars corporate education, knowledge management and innovation management}

\author{
Juliana Alexandre de Oliveira Araújo ${ }^{1}$, Maria de Lourdes da Costa Domingos ${ }^{2}$ \\ ${ }^{1}$ Universidade Federal Fluminense (UFF), Niterói, Rio de Janeiro, Brasil. ORCID: https://orcid.org/0000-0001-7463-6632 \\ ${ }^{2}$ Universidade Federal Fluminense (UFF), Niterói, Rio de Janeiro, Brasil. ORCID: https://orcid.org/0000-0002-5591-7743
}

Autor para correspondência/Mail to: Juliana Alexandre de Oliveira Araújo, juliana85alexandre@gmail.com

Recebido/Submitted: 12 de outubro de 2019; Aceito/Approved: 02 de julho de 2020

Copyright (c) 2020 Araújo \& Domingos. Todo o conteúdo da Revista (incluindo-se instruções, política editorial e modelos) está sob uma licença Creative Commons Atribuição-NãoComercial-Compartilhalgual 3.0 Não Adaptada. Ao serem publicados por esta Revista, os artigos são de livre uso em ambientes educacionais, de pesquisa e não comerciais, com atribuição de autoria obrigatória. Mais informações em http://revistas.ufpr.br/atoz/about/submissions\#copyrightNotice.

\begin{abstract}
Resumo
Introdução: devido às constantes mudanças do cenário corporativo, processos e produtos tendem a ser repensados. Admitindo a educação como elemento de sustentação organizacional, este artigo visa discutir a importância da criação de uma Universidade Corporativa - UC, com base nos Pilares Educação Corporativa - EC, Gestão do Conhecimento - GC e Gestão da Inovação - GI.

Metodologia: a pesquisa adotou a revisão bibliográfica e entrevistas semiestruturadas em uma amostra de três empresas que já possuem UC. Os dados coletados foram submetidos à análise de discurso.

Resultados: houve a confirmação da importância dos Pilares delimitados, com definição de etapas para a concretização da UC. Conclusão: percebeu-se a necessidade de alinhar a oferta de ações educacionais às estratégias da organização, proteger os conhecimentos já construídos e gerar oportunidades para a inovação nas empresas, a fim de ajustá-las às demandas do mercado e clientes. Propõem-se novas pesquisas em instituições privadas e multinacionais, investigando não somente práticas de UC, mas também as peculiaridades de GC e Gl em diferentes contextos.
\end{abstract}

Palavras-chave: Educação Corporativa; Estratégia; Gestão da Inovação; Gestão do Conhecimento; Universidade Corporativa.

\begin{abstract}
Introduction: due to the constant changes in the corporate scenario, processes and products tend to be rethought. Admitting education as an element of organizational support, this article aims to discuss the importance of creating a Corporate University - UC, based on the Corporate Education - CE, Knowledge Management - KM and Innovation Management - IM pillars.

Method: the research adopted a bibliographic review and semi-structured interviews, in a sample of three companies that already have UC. The collected data were submitted to discourse analysis.

Results: there was confirmation of the importance of the defined pillars, with definition of steps for the implementation of the UC.

Conclusions: the need to align the offer of educational actions to the organization's strategies was realized, protecting the knowledge already built and generating opportunities for innovation in companies, in order to adjust them to the demands of the market and customers. New research is proposed in private and multinational institutions, investigating not only UC practices, but also the peculiarities of KM and IM in different contexts.
\end{abstract}

Keywords: Corporative education; Strategy; Innovation management; Knowledge management; Corporate University.

\section{INTRODUÇÃO}

É cada vez mais destacado no discurso contemporâneo que, para a sobrevivência das empresas, em um cenário competitivo e com transformações constantes, são necessárias a busca pela construção de novos conhecimentos, a aprendizagem rápida e a incorporação de novas competências ao negócio (Toni \& Alvares, 2016).

Devido às mudanças da sociedade pós-moderna, vem ocorrendo a modificação da valorização dos funcionários, destacando-se mais sua qualificação mental (Oliva, Roman, \& Mazzali, 2010) do que sua qualificação manual (Meister, 1999). Com base nesta perspectiva, segundo Meister (1999), é preciso adotar a Educação Corporativa EC como um valor e uma prática contínua nas organizações, ressaltando que o conhecimento é uma fonte de formação de riqueza (Eboli, 2004), que gera vantagem competitiva (R. V. D. Gonzalez \& Martins, 2017) para o enfrentamento das dificuldades postas pela complexidade do contexto atual.

As organizações têm apresentado modificações no planejamento e na execução, considerando, além de suas necessidades atuais, as demandas de inovação (Teece, 2009). Corroborando com Teece (2009), os estudos de Abbad e Mourão (2012) apontam que o levantamento das necessidades educacionais precisa não somente contemplar os gaps de desempenho dos empregados, mas também considerar as demandas empresariais futuras, atendendo ao mapeamento das estratégias organizacionais. 
Falsarella e Jannuzzi (2017) destacam a necessidade de planejar o futuro com bases confiáveis e concretas, menos intuitivas, a fim de que a organização sobreviva à competitividade imposta pelo mercado, precisando de novas e rápidas respostas.

Para tanto, é preciso transformar o plano estratégico, que muitas vezes é estático, em um elemento dinâmico, aumentando a comunicação, o engajamento dos funcionários e o acompanhamento contínuo (Suarez, Mora, \& Roldán, 2016).

Freitas (2003) explora em seu estudo as expressões "Universidade Corporativa" e "Educação Corporativa", por meio de significados presentes em legislações e defendidos por determinados autores, priorizando a utilização do segundo termo no cotidiano empresarial. Embora a Lei 9.394 de 20 de dezembro de 2006 direcione o termo "Universidade" para formação superior de indivíduos, a presente pesquisa adota o conceito de Meister (1999), não restringindo a empregados com nível superior, mas considerando todo o público organizacional e seus stakeholders, com a adoção das diretrizes da Educação Corporativa na prática do desenvolvimento humano, já que é um dos Pilares da Universidade proposta nesta pesquisa.

Discutir a importância de uma Universidade Corporativa pautada nos pilares da Educação Corporativa, Gestão do Conhecimento e Gestão da Inovação é o objetivo geral da presente pesquisa. Os objetivos específicos foram base para a elaboração do roteiro da entrevista (Apêndice 1) e encontram-se dispostos a seguir:

a) analisar os termos Educação Corporativa, Gestão do Conhecimento e Inovação;

b) xaminar as melhores práticas, considerando experiências de profissionais que trabalham ou já trabalharam em empresas que possuem UC;

c) especificar a importância das estratégias organizacionais para a prática da Universidade Corporativa; e

d) compreender a relação entre Educação Corporativa, Gestão do Conhecimento e Gestão da Inovação para o desenvolvimento da Universidade Corporativa.

A originalidade do estudo pauta-se no Tripé desenhado e nas dez etapas para a referida implementação, já que a organização "Gerando Valores" apresenta estratégias de crescimento, porém, com um certo distanciamento do desenvolvimento profissional, ressaltando que a empresa adota tentativas para implementar a sua Universidade Corporativa desde o ano 2009, porém, sem sucesso. Portanto, o presente estudo foi desenvolvido com a justificativa de proporcionar oportunidades práticas para a referida instituição, contendo conceitos da literatura e experiências de três empresas da Administração Pública, que já possuem Universidade Corporativa, a fim de responder a seguinte questão norteadora: De que modo a implantação de uma Universidade Corporativa poderá atender às estratégias da organização pública brasileira "Gerando Valores"?

Destaca-se que, para iniciar o Tripé da Universidade Corporativa na "Gerando Valores", são primordiais as estratégias de negócio e o conhecimento destas por parte da área de Educação Corporativa, pois isto propiciará um planejamento educacional e de inovação com foco no que a empresa realmente demanda. A Gestão do Conhecimento é o elemento para perpetuar o saber na empresa ao longo do tempo, a fim de proporcionar um contínuo atingimento dos objetivos traçados por parte das equipes.

\section{MÉTODO}

O presente estudo encontra-se pautado nas teorias sobre Educação Corporativa, Gestão do Conhecimento e Gestão da Inovação e nas necessidades práticas, no âmbito do desenvolvimento humano, da empresa "Gerando Valores". A referida organização atua nos ramos gráfico e metalúrgico, encontra-se localizada no estado do Rio de Janeiro, e corre o risco de ser privatizada nos próximos anos, já que seu lucro líquido não evoluiu no período 2015 a 2018, mesmo tendo orçamento próprio, ou seja, não é dependente financeiramente da União. Na primeira fase do trabalho, a pesquisa bibliográfica foi o método adotado, contribuindo para o levantamento de estudos sobre os temas chave.

Seguindo a proposta de estudos de caso, participaram da amostra desta pesquisa três empresas que possuem Universidade Corporativa, contendo nove profissionais, dentre estes gerentes e profissionais que já foram gestores. A empresa 1 é uma sociedade de economia mista de capital aberto, de grande porte, holding do setor elétrico. A empresa 2 é uma sociedade de economia mista, capital aberto, grande porte e é subsidiária da empresa 1 . A empresa 3 também é uma sociedade de economia mista, grande porte e do ramo do petróleo.

A coleta dos dados secundários ocorreu por meio do levantamento da literatura, realizado com a busca de artigos e dissertações no Google Acadêmico, além da identificação de livros sobre os assuntos abordados. A investigação bibliográfica foi realizada nas bases Scopus e Scielo a partir do 2 de abril de 2018, com foco em artigos, e para cada palavra-chave registrou-se também outras fontes selecionadas, conforme consta no Quadro1. 


\begin{tabular}{|c|c|c|}
\hline $\begin{array}{l}\text { Palavra-chave e Dia da } \\
\text { Bibliometria }\end{array}$ & Filtros nas bases Scopus e SciELO & Outras Fontes \\
\hline $\begin{array}{l}\text { "Universidade Corporativa or } \\
\text { Corporate University" } 2 \text { de abril de } \\
2018 \text { Artigos mais recentes: } \\
2016,2017 \text { e } 2018\end{array}$ & $\begin{array}{c}\text { Artigos mais antigos: 1983,1985 e } \\
1986 \text { Para ampliar a amostra: } 1998 \text { e } \\
1999 \text { já que a UC surgiu no Brasil na } \\
\text { década de } 90 \text { Para ampliar a } \\
\text { amostra: } 2001 \text { e } 2005 \text { por serem } \\
\text { anos de pico de publicação. }\end{array}$ & $\begin{array}{l}1 \text { Dissertação, } 2 \text { livros } \\
\text { e } 5 \text { pesquisas } \\
\text { disponíveis no Google } \\
\text { Acadêmico. }\end{array}$ \\
\hline $\begin{array}{l}\text { "Planejamento Estratégico ou Plano } \\
\text { Estratégico or Strategic Planning"17 } \\
\text { de junho de } 2018\end{array}$ & $\begin{array}{l}\text { Artigos mais recentes: } 2018 \\
\text { Palavra-Chave: Strategic-Planning } \\
\text { Para ampliar a amostra: } 2017\end{array}$ & $\begin{array}{c}1 \text { livro, } 8 \text { artigos } \\
\text { encontrados no Google } \\
\text { Acadêmico. }\end{array}$ \\
\hline $\begin{array}{l}\text { "Gestão do Conhecimento or } \\
\text { Knowledge Management"2 de abril } \\
\text { de } 2018\end{array}$ & Artigos mais recentes: 2018 & $\begin{array}{l}4 \text { livros e } 2 \text { artigos } \\
\text { identificados no } \\
\text { Google Acadêmico. }\end{array}$ \\
\hline $\begin{array}{l}\text { "Gestão da Inovação ot Innovation } \\
\text { Management" } 2 \text { de abril de } 2018\end{array}$ & $\begin{array}{l}\text { Artigos de 2017, já que em } 2018 \text { não } \\
\text { houve artigo na base Scopus Artigos } \\
\text { de } 2017 \text { e } 2018 \text { na base Scielo }\end{array}$ & $\begin{array}{c}1 \text { livro, } 1 \text { Manual e } 14 \\
\text { artigos encontrados no } \\
\text { Google Acadêmico. }\end{array}$ \\
\hline $\begin{array}{l}\text { "Educação Corporativa or Corpc } \\
\text { Education } 20 \text { de dezembro de } 2\end{array}$ & Por Artigos & 2 livros. \\
\hline
\end{tabular}

Quadro 1. Levantamento da literatura.

Fonte: Elaborado pelas autoras (2020).

No que tange ao refino dos artigos detectados no levantamento da literatura, ocorreu, primeiramente, a leitura dos títulos e resumos. Em seguida, houve a leitura das introduções e conclusões, a fim de identificar os artigos mais afins aos temas de composição do presente estudo.

Na segunda fase da pesquisa, ocorreu a coleta de dados primários por meio de entrevistas semiestruturadas, realizadas presencialmente, com gravação de áudio após consentimento dos participantes. O roteiro da entrevista, disposto no Apêndice 1, foi elaborado tomando como base os objetivos específicos da pesquisa e dados coletados na primeira fase, classificados conforme consta no Quadro 2.

\begin{tabular}{|l|l|l|}
\hline Categorias & Objetivo Específico & Autores \\
\hline Conceitos & $\begin{array}{l}\text { Analisar os termos Educação Cor- } \\
\text { porativa, Gestão do Conheci- } \\
\text { mento e Inovação }\end{array}$ & $\begin{array}{l}\text { Eboli (2004) e Meister (1999) para EC Batista } \\
\text { (2012) para GC Chesbrough (2006) para GI }\end{array}$ \\
\hline $\begin{array}{l}\text { Práticas, Dificul- } \\
\text { dades e Conquis- } \\
\text { tas }\end{array}$ & $\begin{array}{l}\text { Examinar melhores práticas por } \\
\text { meio de profissionais que traba- } \\
\text { Iham ou já trabalharam em empre- } \\
\text { sas que possuem UC }\end{array}$ & $\begin{array}{l}\text { Miranda (2015) contemplando aspectos sobre o } \\
\text { funcionamento da UC }\end{array}$ \\
\hline $\begin{array}{l}\text { Implementação } \\
\text { e Manutenção }\end{array}$ & $\begin{array}{l}\text { Especificar a importância das es- } \\
\text { tratégias organizacionais para a a } \\
\text { prática da Universidade Corpora- } \\
\text { tiva }\end{array}$ & $\begin{array}{l}\text { Porter (1996) para conceito de estratégia. Eboli } \\
\text { (2004) e Meister (1999) sobre a UC alinhada às } \\
\text { estratégias organizacionais Falsarella e Jannuzzi } \\
\text { (2017) contemplando a prática do Planejamento } \\
\text { Estratégico Suarez et al. (2016) sobre necessidade } \\
\text { de criar um Plano Estratégico dinâmico. }\end{array}$ \\
\hline Tripé de UC & $\begin{array}{l}\text { Compreender a relação entre } \\
\text { Educação Corporativa, Gestão do } \\
\text { Conhecimento e Gestão da Ino- } \\
\text { vação para o desenvolvimento da } \\
\text { Universidade Corporativa }\end{array}$ & $\begin{array}{l}\text { Meister (1999) e Eboli (2004) apresentando o pro- } \\
\text { cesso de Educação Corporativa Francelino, Pelú- } \\
\text { cio, Monteiro, Barbosa, e Nohan (2012), relacio- } \\
\text { nando UC com Gestão do Conhecimento I. Gonza- } \\
\text { lez (2014), relacionando GC e Gl }\end{array}$ \\
\hline
\end{tabular}

Quadro 2. Estruturação das Entrevistas: categorização e critérios.

Fonte: Elaborado pelas autoras (2020).

Para aprimorar o roteiro da entrevista, ocorreu a realização de entrevista piloto com uma profissional da empresa 2. A inclusão de perguntas conceituais sobre Universidade Corporativa, Gestão do Conhecimento e Gestão da Inovação, assim como a indagação referente às providências para sustentar a UC no tempo, foram contribuições da referida participante. Tomando como referências as teorias de Eboli (2004) sobre EC, alinhadas às estratégias empresariais, e as de Nonaka e Takeuchi (1995) sobre a Criação do Conhecimento, atrelado à Inovação Contínua, foi adotado um Tripé para pensar a UC. O referido Tripé UC apresenta como entradas as estratégias, ou seja, elas possibilitam o funcionamento da UC, sendo utilizadas como subsídios para a oferta dos Pilares EC, GC e GI na empresa. As saídas do Tripé são os resultados, ou seja, são as consequências de se ter uma UC. 


\section{REFERENCIAL TEÓRICO}

\section{Entradas do Tripé: estratégias}

Para Porter (1996), estratégia é uma providência que coloca a organização em destaque perante seus concorrentes. Para Souza, Rezende, e Hardt (2007), estratégia é a adoção de uma maneira eficaz para atingir os objetivos traçados. Segundo Falsarella e Jannuzzi (2017), estratégias referem-se ao caminho a ser trilhado para cumprir objetivos e metas.

Um Plano Estratégico estático encontrado apenas no sítio da empresa, contendo "Missão, Visão, Objetivos, Metas com Indicadores e Estratégias" (Falsarella \& Jannuzzi, 2017) pode ir contra a necessidade de inovar. Para atender ao cenário competitivo e de mudanças contínuas, o Plano Estratégico precisa ser um elemento dinâmico do cotidiano organizacional, posto que serve para acompanhar o atendimento dos objetivos mapeados (Suarez et al., 2016).

Em um cenário competitivo, é essencial traçar estratégias para sustentar a empresa no mercado (I. Gonzalez, 2014). Porém, não é suficiente apenas traçar estratégias, é preciso colocá-las em prática e adaptá-las às demandas organizacionais, as quais estão em constante transformação, dependendo dos clientes e da sociedade (Abbad \& Mourão, 2012).

Após a análise do cenário interno e externo e a aprovação do Plano Estratégico, é preciso organizar os objetivos previstos no Plano Estratégico sob a forma de projetos, a fim de identificar seus responsáveis e agilizar a execução, retirando-os do papel (Falsarella \& Jannuzzi, 2017).

Para aprimorar o atingimento das estratégias mapeadas, é preciso preparar os empregados, por meio de conhecimentos, habilidades e atitudes desenvolvidos a partir da Educação Corporativa.

\section{Pilar: Educação Corporativa (EC)}

Segundo Eboli (2004), há uma mudança de paradigma no que tange à aprendizagem nas organizações em relação ao modelo de Treinamento \& Desenvolvimento - T\&D com o de Educação Corporativa (EC).

O T\&D centraliza-se no indivíduo, no nível tático da empresa, considerando apenas o seu público interno, espaço real para a aprendizagem e o aumento de habilidades. Em contrapartida, a EC desenvolve competências críticas, ou seja, aquelas que colocarão os empregados e a empresa em destaque no mercado, abarca o nível estratégico, o aprendizado organizacional e os espaços real e virtual (Eboli, 2004). As competências se referem às entregas, ou seja, os resultados alcançados pelos funcionários em prol da organização (Dutra, Fisher, \& Eboli, 2001)

Alinhada com Eboli (2004), Freitas (2003) destaca que a Educação Corporativa precisa estar voltada para os objetivos organizacionais e não apenas para o atendimento de um posto laboral ou de uma função específica.

A EC é uma oportunidade para desenvolver os colaboradores com critérios previamente estabelecidos, a fim de aperfeiçoar sua atuação na empresa, com foco em efetividade e eficácia (Mundim, 2002).

Com o intuito de contribuir para a implementação do processo de ensino-aprendizagem (EC), Vieira e Francisco (2012) classificam como importantes duas etapas: obter a decisão dos dirigentes e, posteriormente, efetuar um diagnóstico das competências. Trata-se de observar as competências já existentes na empresa e aquelas necessárias para a geração/sustentação da vantagem competitiva. Para Abbad e Mourão (2012), o planejamento educacional precisa prever, além de necessidades para preencher as lacunas do desempenho atual, as demandas futuras de aprendizagem.

Francelino et al. (2012) detectaram que a EC pode trazer um diferencial competitivo, além de benefícios para os funcionários e comunidade caso seja bem implementada, com foco num processo de aprendizagem contínuo.

Meister (1999, p. 29) faz alusão à UC como um "guarda-chuva estratégico para desenvolver e educar funcionários, clientes, fornecedores e comunidade, a fim de cumprir as estratégias da organização".

Para sustentar a UC nas organizações, é preciso divulgar os benefícios da Universidade, por meio de indicadores que apresentem a interferência das práticas educativas com os resultados da organização (Miranda, 2015). Para tanto, é necessário que seja feita uma relação direta entre o investimento na Educação Corporativa e o resultado no negócio da empresa. Há indícios de que, por mais que esteja alinhada com os objetivos corporativos, a Universidade Corporativa tem a necessidade de uma demonstração mais direta e clara, por meio de indicadores, sobre sua real influência nos resultados (Miranda, 2015, p. 124).

Os conhecimentos construídos por meio da EC precisam ser protegidos e difundidos na organização a fim de que sejam eficazes, de forma contínua, para o atingimento dos objetivos estratégicos e a Gestão do Conhecimento (GC) possui estas funções (proteção e disseminação). 


\section{Pilar: Gestão do Conhecimento (GC)}

Na literatura sobre Gestão de Conhecimento (GC), podemos encontrar duas abordagens diferentes sobre o assunto: uma segue o modelo norte-americano e a outra, o japonês. A primeira foi iniciativa de Davenport e Prusak (1998) e sua ênfase é o conhecimento explícito e formalizado, enquanto a segunda, defendida por Nonaka e Takeuchi (1997), destaca o conhecimento tácito (Carbone, Brandão, Leite, \& Vilhena, 2005)

As classificações que separam conhecimento explícito e tácito são oriundas do trabalho desenvolvido por Polanyi (1966). O conhecimento tácito, relacionado à experiência do funcionário, é aquele em que o indivíduo possui certa dificuldade em transferir o saber aos demais integrantes da equipe, referindo-se a "conclusões, insights e palpites subjetivos". Já o conhecimento explícito "pode ser facilmente "processado"por um computador, transmitido eletronicamente ou armazenado em banco de dados" (Scatolin, 2015, p. 7-8).

Segundo Ribeiro, Soares, Jurza, Ziviani, e Neves (2017), é importante criar um ambiente convidativo para a GC na organização, sendo necessário identificar as práticas adequadas e mobilizar os membros da empresa.

Neste processo, Batista (2012) frisa cinco etapas importantes: identificação, criação, armazenamento, compartilhamento e aplicação. Segundo o autor, a identificação visa levantar as competências organizacionais e verificar os gaps, ao comparar o que é desejado pela empresa e o que os colaboradores realmente possuem de conhecimentos, habilidades e atitudes. A etapa de criação objetiva preencher esses gaps por meio da geração de conhecimentos, ou seja, é o aprendizado. O armazenamento consiste em disponibilizar os conhecimentos em local de fácil acesso a todos e, não sendo possível, é necessária a interação entre colaboradores para que ocorra o aprendizado. O compartilhamento visa criar um ambiente de confiança, propício à troca de conhecimentos entre os colaboradores. A última etapa, da aplicação, refere-se à utilização constante dos conhecimentos tanto nas atividades meio, como nas atividades fim da empresa, ou seja, é a agregação de valor do conhecimento para a organização.

Portanto, a EC desenvolve os funcionários para que eles possam atender às estratégias organizacionais traçadas e a GC organiza e colabora com o compartilhamento e registro dos saberes construídos ao longo da trajetória profissional. No entanto, no contexto atual, não é rara a declaração de que é preciso ir além desses dois Pilares, prospectando as necessidades para o futuro empresarial, em consonância com as demandas do mercado e da sociedade.

\section{Pilar: Gestão da Inovação}

O conceito de inovação evoluiu no tempo, pois, inicialmente, referia-se tão somente à introdução de um produto novo no mercado, ocorrendo a ampliação da sua abrangência a partir da identificação de modificações nos serviços, no marketing e até mesmo na gestão (Bessant, 2003)

A inovação pode ser classificada como radical ou incremental. Segundo Tidd, Bessant, e Pavitt (2005), a primeira - radical - pauta-se no disruptivo, no que é novidade na empresa, ou seja, é o resultado de novas tecnologias, produtos ou processos. Para Henderson e Clark (1990), a inovação radical pode gerar novos mercados ou até mesmo reconstruir determinada indústria. A segunda - incremental - refere-se às melhorias do que já existe, a fim de, por exemplo, conquistar um público ainda resistente a um determinado produto, processo ou serviço (Sbicca \& Pelaez, 2006)

Um ponto importante a ser considerado é que é necessário gerir a inovação a partir de estímulos, planejamento e execução, podendo a captura das ideias e suas implementações ocorrer dentro e fora do âmbito organizacional, conforme características da Inovação Aberta ou Open Innovation (Chesbrough, 2006).

Inovação Aberta ou Open Innovation apropria-se de fontes internas (funcionários) e externas (universidades, centros de pesquisa, fornecedores, determinadas empresas do mesmo campo de atuação etc.), objetivando implementar as inovações na empresa (Chesbrough, 2006). Corroborando com este autor, Tigre (2006) exemplifica as fontes internas e externas para o processo de inovação, conforme consta no Quadro 3.

\begin{tabular}{|l|l|}
\hline Fontes de Inovação & Exemplo \\
\hline Desenvolvimento Tecnológico próprio & P\&D, engenharia reversa e experimentação \\
\hline Contratos de transferência de tecnologia & $\begin{array}{l}\text { Licenças e patentes, contratos com univer- } \\
\text { sidades e centros de pesquisa }\end{array}$ \\
\hline Aprendizado cumulativo & $\begin{array}{l}\text { Processos de aprender fazendo, usando, in- } \\
\text { teragindo etc. devidamente documentado e } \\
\text { difundido na empresa. }\end{array}$ \\
\hline
\end{tabular}

Quadro 3. Fontes de inovação.

Fonte: Adaptado de Tigre (2006).

Percebe-se no Quadro 3 que a Gestão da Inovação está além do desenvolvimento de inovação interna, podendo ter também como parceiros, no processo inovador, os demais stakeholders, ou seja, a inovação pode acontecer 
dentro ou fora dos espaços empresariais, colhendo os frutos do processo inovador, em ambos os casos, por parte da organização.

\section{RESULTADOS}

O Tripé da UC possui como saídas os resultados que a organização adquirirá, com a implementação e manutenção da UC, em prol da perpetuação da instituição, diante da competitividade do mercado.

Para o presente estudo, os resultados constam no retorno das entrevistas e na elaboração das dez etapas para a implementação da UC na "Gerando Valores", conforme consta nos subitens a seguir.

\section{Resultados das entrevistas}

Os Pilares da UC propostos nesta pesquisa foram: Educação Corporativa, Gestão do Conhecimento e Gestão da Inovação, considerando as estratégias organizacionais como pré-requisitos para iniciar o funcionamento deste Tripé. Esses conceitos foram apresentados aos participantes da pesquisa, sendo os resultados tabulados e submetidos à análise de discurso (Gray, 2012).

Sobre Educação Corporativa, registrou-se que, dos nove entrevistados, seis relacionaram o processo de aprendizagem à necessidade de desenvolver os conhecimentos, as habilidades e as atitudes necessárias para os negócios da empresa, ou seja, referem-se aos assuntos que a diferenciarão no mercado, perante seus concorrentes.

Educação Corporativa é incentivar o desenvolvimento das competências mais críticas dos empregados, as que são mais necessárias para o negócio. Educação Corporativa é o desenvolvimento como um todo dos empregados. (Empresa 1, Empregado B)

Educação Corporativa é o processo de educação, a UC é a instituição ou núcleo que executa esse processo. A separação que eu faço é essa. O primeiro ponto que acho fundamental é a vinculação com a estratégia organizacional. (Empresa 1, Empregado D)

Os resultados levantados corroboram com Eboli (2004), que relaciona a Educação Corporativa com o desenvolvimento de competências críticas para que a organização permaneça competitiva no mercado.

Frisa-se que as obras sobre EC levantadas para o presente estudo não enfatizam o desenvolvimento integral do trabalhador, centralizando suas teorias apenas na necessidade de aprender para aperfeiçoar os resultados da organização. Porém, o empregado B destacou que a EC precisa enxergar um desenvolvimento global do indivíduo.

A GC foi observada como um modo de compartilhar o que se sabe, a fim de que a organização não perca conhecimentos que impactam em seus resultados, como por exemplo, com o desligamento de colaboradores. Para que ocorra a disseminação desta dimensão, é preciso criar um ambiente propício, pautado na confiança, conforme apontado por Batista (2012) e corroborado pelos entrevistados.

É você conseguir esse contato, quem é referência no assunto, saber a quem procurar para te ajudar em determinado momento, trocar ideias com alguém, comunidades de práticas, alguém que te ajude em dúvidas que surjam. (Empresa 2, Empregado G).

Você compartilhar o conhecimento do empregado, conseguir estruturar isso de alguma forma, para que outras pessoas consigam utilizar através de práticas informais, é preciso que isso esteja integrado ao dia a dia do empregado, e que ele faça isso naturalmente. (Empresa 2, Empregado F).

Nossa análise também observou que, objetivando alcançar espaço contínuo no mercado, os participantes afirmaram que é preciso ir além da aprendizagem e do compartilhamento de conhecimentos, sendo necessário enxergar as tendências da sociedade e dos atuais e futuros clientes, no que tange a produtos e serviços, em consonância com Teece (2009).

A GI, também aqui investigada, foi definida como a dimensão que visa estimular a apresentação de ideias na empresa por parte dos funcionários e demais stakeholders, para evitar que as entregas organizacionais para o mercado sejam substituídas por outras mais modernas e eficazes. Para o empregado I da empresa 3, inovação é "Tentar otimizar os processos, seja com tecnologia, seja com forma diferente de trabalhar, simplificar, aportar sistemas, bases de dados".

Esses resultados são compatíveis com os conceitos de inovação radical ("tecnologia") e incremental ("forma diferente de trabalhar"), apresentados por Tidd et al. (2005), considerando que é importante para a captura de novos mercados e clientes, incentivar que os stakeholders inovem, seja apresentando algo novo ou uma melhoria para algo já existente (Henderson \& Clark, 1990; Sbicca \& Pelaez, 2006).

A UC, integrada pelos Pilares Educação Corporativa, Gestão do Conhecimento e Gestão da Inovação, sustenta a inovação e a capacitação das pessoas segundo todos os entrevistados, exemplificado nos trechos destacados a 
seguir: "Sim, Sim. Com certeza. Tudo a ver". (Empresa 1, Funcionários A e B). "Claro. Você só consegue a continuidade do negócio quando você consegue associar essas três". (Empresa 3, Funcionário I) "Sim, sem dúvida. Acho que trabalham junto. O conhecimento propicia inovação. As ferramentas de Gestão do Conhecimento só aumentam essa possibilidade de gerar inovação". (Empresa 2, Funcionária G). Embora unânime, a UC também apresenta dificuldades em sua implementação prática, identificadas no próximo tópico.

A dificuldade central identificada ao longo das entrevistas é a de conseguir sustentar a UC no tempo, fato este alertado desde a entrevista piloto. Neste sentido, os participantes relatam que é preciso estar atento para os seguintes itens: ter orçamento, uma equipe capacitada em Educação Corporativa, parcerias internas e externas, tecnologia para automatizar algumas atividades (envio automático de e-mail para alunos de determinado curso, emissão de certificados on-line, consolidação das avaliações de satisfação, elaboração de relatórios com indicadores, dentre outras) e implementar a educação a distância.

Quanto às práticas, percebeu-se que as três empresas pesquisadas possuem um planejamento educacional, que é construído por meio da equipe responsável e de seus clientes internos. Depois de definido, este planejamento é aprovado pela Direção da organização, para liberar o orçamento que será usado no desenvolvimento profissional.

Ao longo do levantamento de dados, foram identificados três instrumentos de gestão que definem o planejamento: Plano de Carreiras, Plano Estratégico e Avaliação de Desempenho. O primeiro informa as competências referentes à atuação de cada pessoa, tomando como base suas atribuições no cargo. O segundo registra os caminhos a serem perseguidos pela instituição nos próximos anos. O terceiro seleciona os gaps que o funcionário possui, ou seja, em que ele precisa melhorar.

A empresa 2 apresenta sete segmentos em seu planejamento educacional: estratégico, idiomas, liderança, saúde e segurança, projetos, área de negócio e Plano de Desenvolvimento Individual (PDI). Registra-se que todos os segmentos são alimentados pela equipe de Educação Corporativa, tomando como base instrumentos de gestão e demandas da organização, exceto a "saúde e segurança" e "área de negócio". Esses segmentos são alimentados com ações educacionais, tomando como essenciais demandas de instrumentos de gestão, da Direção, de exigência legal e dos clientes internos.

A empresa 3 não somente identifica os conhecimentos e competências críticas, como também as ferramentas para o respectivo atendimento, subsidiando a tomada de decisão de cada gestor, e seleciona o que é necessário para a sua equipe. Uma prática identificada apenas na UC desta empresa foi o serviço técnico especializado. Ele consiste em resolver problemas na área demandante, transformando-os em um case educacional, ou elaborando um vídeo ou uma apostila, a fim de disseminar a aprendizagem para os demais membros da equipe. Com isto, a intenção é capacitá-los para criar futuras soluções sobre o mesmo assunto.

Detectou-se que todas as Universidades possuem indicadores quantitativos para acompanhamento de seus resultados, como por exemplo, homem hora treinado, horas treinadas, investimento, quantitativo de participantes e de participações. O único entrevistado que destacou a importância de um indicador voltado para o resultado da ação educacional foi o funcionário $\mathrm{J}$ da empresa 3 , citando a relação entre o aumento da oferta de um curso sobre segurança no trabalho e a diminuição dos acidentes de trabalho. Encontra-se a seguir o relato do funcionário A da empresa 1, destacando que o compartilhamento dos resultados é feito principalmente com a Diretoria:

Horas de treinamento, quantidade de treinamentos, custos, estatísticas por empresas, report anual. Temos por ciclo e por ano, mas precisamos ter o histórico. Acho importante registrar para ter uma noção do resultado que muita das vezes precisa ser substanciado com números. Compartilhamento: mais com a diretoria. (Empresa 1, Funcionário A).

Esse resultado coincide com a posição de Miranda (2015), que frisa a importância da abrangente divulgação dos indicadores, a fim de que ocorra a percepção do papel benéfico que a UC tem para as organizações. Um indicador de retorno sobre a oferta de ações de desenvolvimento pode ser a Pesquisa de Clima Organizacional, utilizada como um termômetro para averiguar a percepção dos integrantes da empresa sobre a Educação Corporativa, conforme destacado pelo funcionário D da empresa 1.

Sobre as práticas de GC por parte da UC, verificou-se que todas as empresas da amostra apresentam ações de GC. Porém, para que a GC permaneça viva, é necessário um incentivo contínuo. Exemplificações fornecidas pela funcionária A da empresa 1 sobre as metodologias associadas ao ato de disseminar e/ou registrar o conhecimento foram: "Fóruns de Discussão, Mapeamento de Conhecimento, Comunidades de Práticas, Bases de Conhecimentos, Banco de Especialistas (que a gente chama de Meu Perfil), FACs (Perguntas e Respostas mais frequentes)".

Percebeu-se, ao longo das entrevistas, que os resultados da UC podem ser mensurados por meio de indicadores, no que tange ao desenvolvimento profissional, à transparência dos conhecimentos construídos e a partir do repasse e registros de conhecimentos e das ideias implementadas, em prol do aperfeiçoamento da empresa no mercado.

No que tange às conquistas da UC, as respostas foram diversificadas. Versaram sobre ter pessoas capacitadas, alinhamento dos conhecimentos com as estratégias da empresa. A questão de ter um planejamento e o orçamento 
centralizado na área de educação foi identificada como necessária, devido à mudança na cultura da organização.

O serviço técnico educacional, presente na empresa 3, é um benefício, no que tange à solução de problemas, como se pode verificar no depoimento a seguir.

O serviço técnico educacional é a atuação da universidade lá na ponta. A unidade de Espírito Santo estava com problema. Então solicitou que um profissional fosse lá para estudar a situação, pegou todas as informações, trabalhou junto com eles e falou o seguinte, se o gerenciamento desse reservatório você apontar essas ações aqui, é provável que dê um resultado diferente, você reduza o declínio disso. Bom, o que aconteceu, ele foi lá, treinou as pessoas como se fosse um estudo de caso, e a coisa mudou totalmente. Você tinha a expectativa de uma queda de produção e ela se reverteu. Isso trouxe um ganho econômico para a empresa. Mas a conquista a gente diz o seguinte, o ganho é deles, é da área, não é nosso. Mas a conquista é a seguinte: essa experiência vivida ela é adaptada ou para você promover um novo curso e oferecer ou para você adaptar cursos existentes. O nosso ganho é esse, você dar dinamismo nas ações de desenvolvimento também em função de serviços técnicos que você presta. (Empresa 3, Funcionário I).

\section{Proposta de Universidade Corporativa (UC)}

Considerando os Pilares estudados neste artigo, por meio dos autores selecionados para o referencial teórico e os depoimentos levantados ao longo das entrevistas, encontra-se a seguir uma proposta de Universidade Corporativa para as organizações.

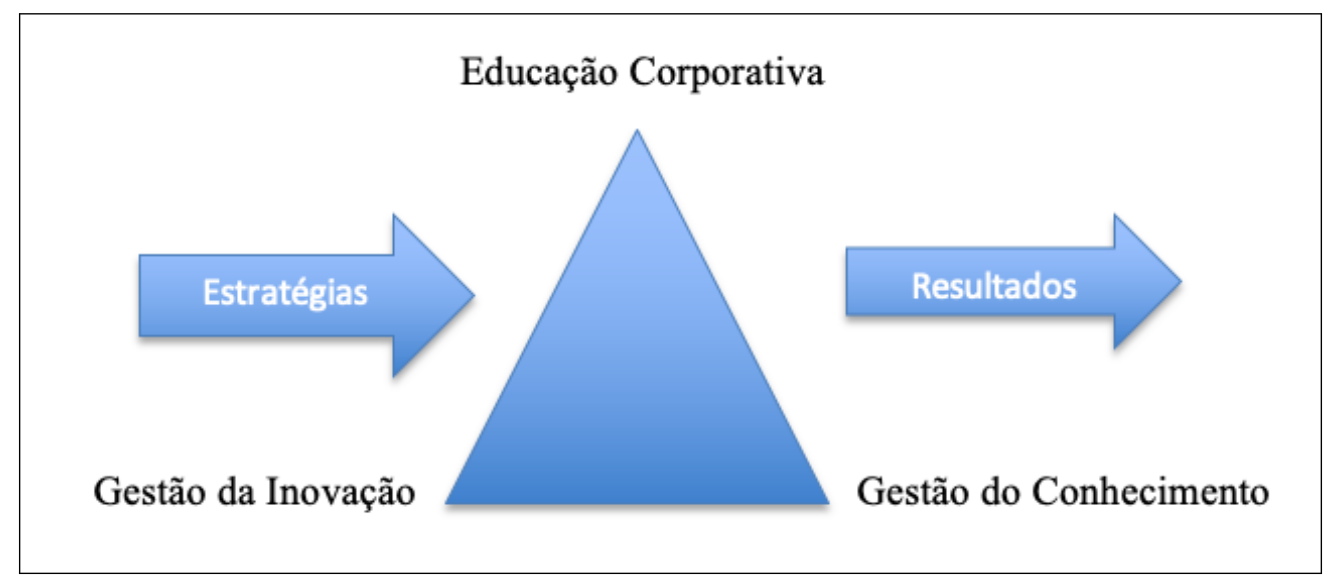

Figura 1. Tripé UC.

Fonte: As autoras (2020).

Tomando como base este Tripé, a análise teórica dos Pilares e os resultados identificados na pesquisa de campo, sugere-se a elaboração de 10 etapas para a implementação da UC nas organizações.

A $1^{\text {a }}$ etapa consiste em capacitar a equipe educacional no que tange aos Pilares do Tripé UC: Educação Corporativa, Gestão do Conhecimento e Gestão da Inovação.

A $2^{\text {a }}$ etapa é o levantamento dos objetivos estratégicos junto à Alta Direção da instituição. Estas ações estão associadas à Educação Corporativa que, segundo Meister (1999), objetiva desenvolver os stakeholders para o atingimento dos objetivos estratégicos.

A $3^{\text {a }}$ etapa refere-se à necessidade de criar um grupo de trabalho, a fim de apresentar um plano de ação para que a Alta Direção patrocine sua implantação, fato essencial para o início e sustentação da UC (Vieira \& Francisco, 2012).

A $4^{\text {a }}$ etapa é o mapeamento das competências críticas e das necessidades de inovação da empresa. No que tange às competências críticas, Batista (2012) observa ser preciso identificar as lacunas de conhecimento da organização, comparando o que é desejado com o que já existe. Ao levantar as necessidades de inovação, Teece (2009), aponta um planejamento educacional direcionado para as demandas momentâneas e para as novas demandas.

A $5^{\text {a }}$ etapa pauta-se na sugestão de Miranda (2015), no que tange ao desenho dos indicadores de desempenho da UC, precisando acompanhá-los e divulgá-los, a fim de demonstrar os resultados da UC, em prol do desenvolvimento organizacional. Para tanto, é preciso priorizar os indicadores de resultado, como por exemplo:

- Atingimento dos objetivos específicos das ações educacionais na prática profissional e organizacional. Não basta a equipe elaborar o projeto do curso, é preciso acompanhar o resultado do curso na empresa; 
- Pesquisa de Clima Organizacional, verificando se os empregados estão mais satisfeitos no que tange ao desenvolvimento profissional e pessoal;

- Comparativo entre ideias fornecidas e ideias implementadas, a fim de direcionar a UC para ações de inovação e não apenas para ações de formação profissional; e

- Quantitativo de conhecimentos críticos devidamente registrados e compartilhados na organização.

A $6^{\text {a }}$ etapa é a elaboração do planejamento educacional, tomando como base o mapeamento de conhecimentos críticos, a necessidade de inovação e de qualidade de vida, tendo como o público-alvo não somente os funcionários da organização, como também os stakeholders. Esse planejamento, somado aos benefícios da UC estudados ao longo do item 7.4, práticas de GC e indicadores de desempenho, precisará ser apresentado para a Alta Direção para que ela patrocine a implementação e a sustentação da UC. Isso visa também incentivar o comprometimento de todos com o autodesenvolvimento, o registro e o repasse dos conhecimentos e a identificação/implementação de ideias para a evolução organizacional. Esse patrocínio foi destacado como uma chave de sucesso da UC por parte de cinco dos nove entrevistados, item reconhecido também por Vieira e Francisco (2012)

A $7^{\text {a }}$ etapa refere-se à implementação de um Portal Tecnológico que permita automatizar as atividades da equipe educacional, receber e disponibilizar ideias dos stakeholders, possibilitar o compartilhamento dos conhecimentos construídos e adotar a educação a distância. Este passo baseia-se no viabilizador "Tecnologia" (Batista, 2012), na necessidade de adotar as Novas Tecnologias de Informação e Comunicação na educação (Mundim \& Ricardo, 2004), e na possibilidade de praticar o princípio "Disponibilidade" (Eboli, 2004), abarcando diferentes públicos, no que tange à oferta de ações educacionais, já que a aprendizagem poderá ser presencial ou a distância.

A $8^{\mathrm{a}}$ etapa requer sensibilizar todos os colaboradores da empresa, no que tange aos benefícios da UC e aos papéis de cada um. Esta fase encontra-se em consonância com o princípio "parceria" nomeado por Eboli (2004). Para sustentar a UC é preciso firmar parceiros internos (líderes-educadores e funcionários dispostos ao autodesenvolvimento) e externos (universidades acadêmicas e outras universidades corporativas).

A $9^{\text {a }}$ etapa é praticar o planejamento educacional, com ações de desenvolvimento e de GC, conforme ocorre na empresa 2. Além disso, nesta etapa ocorre o acompanhamento das ideias recebidas até a sua implementação na empresa, caso isso seja favorável para os resultados almejados.

A $10^{\text {a }}$ etapa, em consonância com a proposta de Miranda (2015), é a divulgação dos resultados da UC e do acompanhamento contínuo da evolução dos indicadores da UC, a fim de demonstrar a todos seus benefícios e efetuar os ajustes necessários, tanto no planejamento educacional, como nas práticas.

Ressalta-se que as etapas anteriores foram pensadas como proposta para a empresa pública "Gerando Valores", considerando as seguintes necessidades: de se reinventar perante o mercado e a sociedade e de proteger as especificidades dos conhecimentos sobre suas atividades. A proposta pode ser alterada tanto em sua teoria, como em sua ordenação, adaptando-se às características e cultura de cada organização.

\section{CONSIDERAÇÕES FINAIS}

O presente estudo objetivou discutir a importância de uma UC pautada nos Pilares Educação Corporativa, Gestão do Conhecimento e Gestão da Inovação, a fim de possibilitar o resgate da atividade-fim de uma empresa pública e sua sustentação perante o mercado. Observou-se que um dos benefícios da UC é o alinhamento dos funcionários às estratégias da organização, por meio da aplicação da Educação Corporativa. Além disso, a necessidade de proteger os conhecimentos construídos e de inovar para ajustar a organização às novas demandas contextuais, podem ser consideradas justificativas para a adoção de uma UC. A EC, GC e GI mostraram-se importantes pilares na composição de um Tripé para sustentar a UC, sendo as estratégias consideradas a entrada ou início de seu funcionamento e a saída, os resultados/benefícios que se espera obter.

Estudos sobre estes temas levaram a pensar em 10 etapas para organizar a implantação e o funcionamento de uma UC para uma instituição pública. No entanto, trata-se apenas de um possível caminho, posto que a pequena amostra investigativa, composta de apenas três empresas com o mesmo vínculo com a Administração Pública, foi um dos limitadores desta pesquisa. Além disso, o estudo limita-se por não ter observado, de forma mais específica, as necessidades detalhadas da empresa fictícia "Gerando Valores", concentrando-se no resgate de uma vantagem competitiva, após observar a não evolução de seu lucro líquido entre os anos 2015 e 2018 . A ênfase neste procedimento justifica-se pela urgência que a perda de competividade das instituições governamentais no mercado ressalta, já que, mesmo sendo uma empresa pública, em alguns casos é possível haver concorrência quanto aos produtos que ela produz.

Portanto, sugere-se que novos estudos sejam realizados, acrescentando a coleta de novos dados e melhores práticas em Universidades Corporativas pertencentes a empresas públicas, privadas e multinacionais. É importante verificar a adaptabilidade do modelo de aplicação do Tripé da UC em organizações distintas e estudar sua contribuição para o conhecimento e a inovação, tendo em mente que são cada vez maiores as exigências que equacionam a relação setor público e mercado na sociedade atual. 


\section{APÊNDICE 1 - LEVANTANDO MELHORES PRÁTICAS SOBRE UNIVERSIDADE CORPORA- TIVA (UC)}

1. No seu entendimento, o que é Educação Corporativa e Universidade Corporativa - UC?

2. Quando ocorreu a implementação da UC?

3. Por quê surgiu a UC na empresa? Quais foram os procedimentos para a implementação?

4. O que é essencial para conseguir a sustentação da UC ao longo do tempo?

5. Como são realizados o planejamento e a oferta de ações educacionais aqui na sua empresa? Há quantas pessoas na equipe? Qual a formação dos membros?

6. São realizadas parcerias? Com que instituições?

7. Quais os desafios (dificuldades) da UC ou das ações Educativas na empresa?

8. Quais as conquistas (benefícios) da UC na empresa?

9. Para você, o que é Gestão do Conhecimento?

10. A Universidade Corporativa possui práticas de Gestão do Conhecimento? Caso positivo, quais?

11. No seu entendimento, o que é Inovação?

12. A Universidade Corporativa está relacionada com Gestão da Inovação? Caso positivo, como?

13. Como são avaliados os resultados da Universidade Corporativa? São usados indicadores? Quais? Com que frequência? Com quem são compartilhados?

14. Considerando sua experiência, é possível, na prática, associar a Universidade Corporativa com Gestão do Conhecimento e Gestão da Inovação? 


\section{REFERÊNCIAS}

Abbad, G. d., \& Mourão, L. (2012). Avaliação de ncessidades de td\&e: proposição de um novo modelo. Revista de Administração da Mackenzie, 13 (6 esp), 107-137. Recuperado de http://editorarevistas.mackenzie.br/index.php/ RAM/article/view/3339.

Batista, F. F. (2012). Modelo de gestão do conhecimento para a administração pública brasileira: como implementar a gestão do conhecimento para produzir resultados em benefício do cidadão/fábio ferreira batista. Brasília: IPEA.

Bessant, J. R. (2003). High-involvement innovation: building and sustaining competitive advantage through continuous change. New Jersey: Wiley.

Carbone, P., Brandão, H. P., Leite, J. B. D., \& Vilhena, R. M. P. (2005). Gestão por competências e gestão do conhecimento. Rio de Janeiro: FGV.

Chesbrough, H. W. (2006). Managing innovation and change. Recuperado de https:// books.google.com.br/books?hl=ptBR\&lr=\&id= eVptX3b_sKgC\&oi $=$ fnd $\& p g=$ PA $127 \& d q=$ The + era + of + open + innovation\&ots $=\mathrm{WbCyBheW}-\mathrm{x} \& \operatorname{sig}=\mathrm{s} 8 \mathrm{yzq} \%$ 20OY1IUAuP_t9qEDVmufzN8 $\# \mathrm{v}=$ onepage $\& \mathrm{q}=\mathrm{The} \%$ 20era\%20of\%20open\%20innovation\&f=false.

Davenport, T. H., \& Prusak, L. (1998). Conhecimento empresarial: como as organizações gerenciam o seu capital intelectual. São Paulo: Campus.

Dutra, J. S., Fisher, A. L., \& Eboli, M. (2001). Gestão por competência: um modelo avançado para gerenciamento de pessoas. São Paulo: Gente.

Eboli, M. (2004). Educação corporativa: mitos e verdades. São Paulo: Gente.

Falsarella, O. M., \& Jannuzzi, C. A. S. C. (2017). Planejamento estrat 'egico empresarial e planejamento de tecnologia de informação e comunicação: uma abordagem utilizando projetos. Gestão e Produção, 24(3), 610-621. doi: 10.1590/0104-530X481-16.

Francelino, V. O., Pelúcio, N. S., Monteiro, A. S., Barbosa, M. V., \& Nohan, C. I. (2012). Educação corporativa e seus benefícios às organizações e aos colaboradores: um estudo de caso da natura. In Simpósio de excelência em gestão e tecnologia. Rezende, Rio de Janeiro, Brasil.: Associação Educacional Dom Bosco.

Freitas, M. C. D. (2003). Educação corporativa: um método de apoio à decisão para implantação nas organizações empresariais. (Tese de doutorado). Universidade Federal de Santa Catarina, Brasil.

Gonzalez, I. (2014). Proposta de um modelo de formação de estratégia de negócio com base na integração entre aprendizagem organizacional e gestão da inovação. (Tese de doutorado). Universidade Metodista de Piracicaba, Brasil.

Gonzalez, R. V. D., \& Martins, M. F. (2017). O processo de gestão do conhecimento: uma pesquisa teórico-conceitual. Gestão e Produção, 24(2), 248-265. doi: 10.1590/0104530X0893-15.

Gray, D. E. (2012). Pesquisa no mundo real. Porto Alegre: Penso.

Henderson, R. M., \& Clark, K. B. (1990). Architectural innovation: the reconfiguration of existing product technologies and the failure of established firms. Administrative Science Quarterly, 35(1), 09-30.

Meister, J. C. (1999). Educação corporativa: a gestão do capital intelectual através das universidades corporativas. São Paulo: Makron Books.

Miranda, M. M. S. d. (2015). Universidade corporativa e sua influência no resultado da empresa: uma análise qualitativa de estudo multicasos em empresas do varejo no estado do rio de janeiro. (Dissertação de mestrado). Universidade Federal Fluminense, Niterói, Rio de Janeiro, Brasil..

Mundim, A. P. F. (2002). Desenvolvimento de produtos e educação corporativa. São Paulo: Atlas.

Mundim, A. P. F., \& Ricardo, E. J. (2004). Educação corporativa: fundamentos e práticas. Rio de Janeiro: Qualitymark.

Nonaka, I., \& Takeuchi, H. (1995). The knowledge-creating company: How japanese companies create the dynamics of innovation. New York: Oxford University Press.

Nonaka, I., \& Takeuchi, H. (1997). Criação de conhecimento na empresa. Rio de Janeiro: Campus.

Oliva, E., Roman, V., \& Mazzali, L. (2010). A universidade corporativa como instrumento de sustentação do negócio: A experiência das empresas estatais. Revista Portuguesa e Brasileira de Gestão, 9(1-2), 75-84.

Polanyi, M. (1966). The tacit dimension. London: Routdedge and Kegan Paul.

Porter, M. E. (1996). What is strategy? Harvard Business Review, 74 (6), 61-67.

Ribeiro, J. S. A. N., Soares, M. A. C., Jurza, P. H., Ziviani, F., \& Neves, J. T. R. (2017). Gestão do conhecimento e desempenho organizacional: Integração dinâmica entre competências e recursos. Perspectivas em Gestão e Conhecimento, 7 (esp), 4-17.

Sbicca, A., \& Pelaez, V. (2006). Sistemas de inovação. In Economia da inovação tecnológica (2a. ed.). São Paulo: Hucitec.

Scatolin, H. G. (2015). A gestão do conhecimento nas organizações: o legado de nonaka e takeuchi. Perspectivas em Gestão e Conhecimento, 5(2), 4-13.

Souza, A. C. S. d., Rezende, D. A., \& Hardt, C. (2007). Estratégia, planejamento de municípios e gestão metropolitana. RAI: Revista de Administração e Inovação, 4(1), $21-39$.

Suarez, E., Mora, A. C., \& Roldán, J. L. (2016). The role of strategic planning in excellence management systems. European Journal of Operational Research, 248(2), 532542. Recuperado de https://www.sciencedirect.com/science/ article/abs/pii/S0377221715006414.

Teece, D. J. (2009). Dynamic capabilities strategic management. New York: Oxford University Press.

Tidd, J., Bessant, J., \& Pavitt, K. (2005). Managing innovation. integrating technological, market and organizational change. New Jersey: Wiley.

Tigre, P. B. (2006). Gestão da inovação: a economia da tecnologia no brasil. Elsevier: Rio de Janeiro.

Toni, K. C. W., \& Alvares, L. M. A. R. (2016). Educação corporativa na perspectiva da inteligência organizacional. Revista Informação \& Informação, 21(3), 228-257. doi: 10.5433/1981-8920.2016v21n3p228.

Vieira, F. H. A., \& Francisco, A. C. (2012). Etapas da implementação da educação corporativa e seus impactos em empresas brasileiras: um estudo multicaso. Production, 13 (6 esp), 107-137. doi: 10.1590/S0103-65132012005000018. 
Como citar este artigo (APA):

Araújo, J. A. \& Domingos, M. L da C. (2020). Uma proposta de universidade corporativa pautada nos pilares educação corporativa, gestão do conhecimento e gestão da inovação. AtoZ: novas práticas em informação e conhecimento, 9(1), 42 - 53. Recuperado de: http://dx.doi.org/10.5380/atoz.v9i1.69660 